\title{
A Preliminary Evaluation of Multiple-Choice Sentences Developed for Auditory Training
}

\author{
Jang Won Lee, Dong Woon Yi, Junghak Lee, Jae Hee Lee \\ Department of Audiology, Hallym University of Graduate Studies, Seoul, Korea
}

\section{청능훈련용 객관식형 문장음원의 예비평가}

이장원 · 이동운 · 이정학 · 이재희

한림국제대학원대학교 청각학과

\begin{abstract}
Purpose: Auditory training using multiple-choice items allows easy manipulation of difficulty level, efficient scoring, and analysis of incorrect response patterns. The purpose of this study was to develop multiple-choice sentences as a closed-set material for auditory training. Methods: Each sentence was a five-word sentence (name, adjective, object, numeral, verb). Each of the 5 words contained 10 alternatives, resulting in 50 response alternatives (10 names, 10 adjectives, 10 objects, 10 numerals, 10 verbs). The construction of sentences, the selection of target words and speaker as well as the processes of recording, cutting and resynthesis were based on the recommendations of the International Collegium of Rehabilitative Audiology. In total, 1,500 sentences were generated from a combination of the 50 response alternatives. Results: Twenty-two adults with normal hearing participated in the preliminary evaluation of multiple-choice sentences. After hearing each five-word sentence, listeners were required to choose the five words they had heard from the 50 response alternatives. To verify the applicability of those closed-set sentences in the background noise, evaluation was conducted in quiet as well as under background noise conditions. Results showed that the multiple-choice sentences developed in this study were identified with mean accuracy greater than $95 \%$ in all conditions. Conclusion: Our ten-alternative multiple-choice sentences could be used as stimuli for closed-set auditory training. The multiple-choice sentences could be encouraging especially for hearing-impaired listeners who have difficulty in receiving open-set auditory training. Further research is needed to determine the clinical feasibility of our multiple-choice auditory training for older people with hearing loss.
\end{abstract}

Key Words: Multiple-choice sentence, Auditory training in noise, Closed-set auditory training.

Received: April 4, 2016 / Revised: April 9, 2016 / Accepted: April 12, 2016

Correspondence: Jae Hee Lee, Department of Audiology, Hallym University of Graduate Studies, 405 Yeoksam-ro, Gangnam-gu, Seoul 06198, Korea Tel: +82-2-2051-4952 / Fax: +82-2-3451-6618 / E-mail: leejaehee@hallym.ac.kr

\section{INTRODUCTION}

청각장애를 가진 경우, 난청으로 인한 의사소통의 불편함을 해소하기 위해 보청기와 인공와우 등의 보장구 착용을 시도하게 된다. 보청기 기술의 발달로 신호대잡음비(signal-to-noise ratio, $\mathrm{SNR}$ ), 가청 정도(audibility), 음질(sound quality) 등이 개선되 어 왔으나 보청기 착용만으로 난청인의 소음 하 의사소통 능력 이 만족스럽게 개선되지 않는 한계점이 있다(Burk \& Humes, 2008). 그 이유는 보청기가 음향학적으로 SNR을 개선시켜주나 개선된 SNR을 의사소통 시 효과적으로 활용할 수 있는지의 여 부는 기계가 아닌 난청인의 청각 인지능력에 좌우되기 때문이다. 보청기 착용만으로 의사소통의 어려움이 해결되지 않는 경우
청능훈련을 함께 받는 것이 중요하다(Burk \& Humes, 2008; Henshaw \& Ferguson, 2013; Morais et al., 2015; Stecker et al., 2006). 청능훈련을 실시한 국내 연구결과를 종합해보면 서 로 다른 자극음을 사용하였음에도 불구하고 6 10주의 청능훈 련을 받은 후 보청기 착용군의 어음인지능력이 유의하게 향상 하였다(Cho et al., 2013; Kim \& Lee, 2010; Kwon, 2014; Lee, 2011; Yeo et al., 2014). 이러한 실증적 연구(evidence-based study)의 결과들로 청능훈련의 중요성이 강조되어 왔으나 국내 의 경우 국외에 비해 훈련의 목적으로 체계적으로 개발된 청능 훈련 도구가 비교적 부족한 실정이다.

문장을 이용하여 종합적 훈련을 시행한 여러 선행연구에서 문장을 통한 훈련이 일상생활의 인지능력 향상에 유의한 도움 
을 주었다고 보고하였다(Cho et al., 2013; Kwon, 2014; Yeo et al., 2014). 대부분의 선행연구에서 국내 청능훈련용 문장 도구 의 부족으로 한정된 개수의 문장을 훈련에 활용하였고, 반복 된 훈련을 시행할 경우 훈련 대상자가 문장을 예측 가능하다 는 한계점을 밝혔다. Humes et al.(2014)은 청능훈련의 도구 중 하나로 5개 단어로 구성된 Hagerman-format 객관식형(multiple-choice) 문장을 사용하였다. 각 단어당 10 개의 보기가 있 고 이를 통해 조합이 가능한 문장의 수가 $10^{5}$ 개이므로 대상자 가 훈련용 문장을 외우거나 예측하기 어렵다. 이와 같이 객관식 형 문장을 이용할 경우 보기 없이 들은 단어를 고르는 데 어려 움을 보이는 대상자에게도 활용가능하다.

따라서 본 연구에서는 문장을 구성하는 5 개의 단어를 보기 안에서 선택하는 객관식형(multiple-choice) 문장목록을 개발 하고, 청능훈련의 목적으로 활용가능한지 예비평가를 시행하였 다. 객관식 문장을 통해 보기가 있는 페쇄형 청능훈련을 시행할 경우 보기의 개수 혹은 듣기조건을 변경하는 것이 용이하며, 대 상자의 오류패턴을 파악하는 데 용이하다는 장점이 있다. 각 문 장에 포함된 5 개의 단어를 집중하여 듣고 들은 단어를 기억하고 선택해야 하므로 청자의 단기기억력 및 주의집중력을 개선하는 데 긍정적인 역할을 할 수 있겠다.

\section{MATERIALS AND METHODS}

\section{연구 대상}

총 22 명(남 13 명, 여 9 명)의 건청 대상자가 문장 음원의 개발 을 위한 검증에 참여하였다(평균 연령: 34.2세, 범위: 24 56세). 대상자 모두 250 8,000 Hz 옥타브 단위의 주파수에서 양이 순 음청력역치가 $15 \mathrm{~dB}$ HL 이하였고(Acoustic Analyzer AA1200; Starkey Hearing Technologies, Eden Prairie, MN, USA) 육 안 관찰 시 외이도와 고막에 이상 소견을 보이지 않았다.

\section{문장음원의 개발 및 검증 절차}

객관식형 문장음원의 개발은 문장을 구성하는 단어의 수집, 문장의 적절성 검증, 문장음원의 녹음 및 편집, 문장의 검증 순 으로 진행하였다.

1단계: 문장 내 단어의 수집 및 선정

본 연구에서는 객관식형 문장목록을 구성하기 위해 각 문장 이 동일한 구조를 가지도록 하였다. 문장목록의 전반적인 구성 (general construction), 단어 선택(word selection), 화자 선택, 녹음 및 합성 등을 위하여 International Collegium of Rehabilitative Audiology (ICRA)가 제시한 추천사항을 참고하였다 (Akeroyd et al., 2015).
각 문장은 “주어(name), 형용사(adjective), 목적어(object), 수 사(numeral), 동사(verb)"의 순서로 단어가 나열되도록 구성하 였다. Appendix에 제시한 예시로 살펴보면, 15 개의 단어 보기의 조합으로 "건우는(주어) 새로운(형용사) 책상(목적어) 두 개를(수 사) 산다(동사)” "혹은 “철수는(주어) 작은(형용사) 바구니(목적어) 여덟 개를(수사) 받았다(동사)”의 문장 생성이 가능하다.

먼저, ICRA (Akeroyd et al., 2015)의 추천사항을 참고하여 50 개 보기를 위한 예비 단어를 선정하였다. 선정 과정 시 연령, 학력에 상관없이 다양한 대상자가 훈련에 참여할 수 있도록 아 래의 기준을 고려하여 단어를 수집하였다.

(1) 훈련 시 단기기억의 영향을 고려하여 최대 4음절 이내의 단어 선택

(2) 일상생활에서 자주 사용되는 고빈도 어휘에서 단어 선택 (참고: 한국어 사용빈도, 한국어 기본어휘 의미 빈도 사전)

(3) 문장 내 어휘의 의미적 중립성 고려. 특히 전쟁, 성, 정치 와 관련된 단어 제외

(4) 대법원에서 집계한 선호하는 출생자 이름 및 개명 시 선 호하는 이름 현황 고려

(5) 주어에 해당하는 이름 선정 시 주어 뒤의 “ 는", “ 가"의 개수 균형화

(6) 주어에 해당하는 이름 선정 시 남녀 성별에 따른 이름 균 형화

(7) 명사, 수사, 동사에 해당하는 단어 선정 시 아동도 이해 가 능한 어휘에서 선택(참고: 한국어 초급 교재의 어휘 빈도 와 반복 및 반복 간격에 관한 연구, 등급별 국어 교육용 어 휘 등)

(8) 동사에 해당하는 단어 선정 시 현재형( 한다)과 과거형( 했다)의 개수 균형화

(9) 단어 조합 시 동시조음(coarticulation), 연음 등의 자연스 러움 고려, 맞춤법 표기에서 발음 표기로 전환하여(참고: 국립국어원 표준어 규정, 표준국어대사전) 과다한 경음화 현상 등 발음상의 문제점 고려

(10) 단어 내 음소의 균형과 한국어 음소 분포와의 유사성 고려 위의 기준을 참고하여 보기당 100 개의 단어, 총 500 개의 단 어를 1 차 추출하였다. 본 객관식형 문장의 경우 단어의 조합으 로 완성되는 문장을 제시하게 되므로 각각의 단어뿐 아니라 단 어의 조합으로 이루어지는 문장의 문법 및 의미상 부적절하거 나 부자연스러운지를 확인하여 해당 단어를 삭제하는 예비 실 험을 진행하였다.

예비 실험을 통해 500 개 단어 중 총 100 개의 단어를 2 차 선 정하였고 ICRA의 추천사항에 따라 최대한 단어 내 음소분포 가 한국어 음소 분포와 유사한지를 확인하였다. 음소분포를 확 인하기 위해 먼저 음소 빈도와 음절 분석을 시행하였다. 말소리 
및 음절 빈도 분석을 위해 언어 빈도 분석 프로그램인 'SynKDP 1.5.2 (Synthesized Korean Data Processor 1.6, 일명 깜짝 새)'를 활용하였으며(Shin, 2008), 음소 빈도 분석을 위해 312,651 개의 한국어 음절 말뭉치를 토대로 한 Byun et al.(2005)의 결 과를 참고하였다.

선행 연구에서 발표한 음소 분포와 최대한 유사하도록 본 연 구의 문장 내 단어를 선정하였고, 2 차 선정된 100 개 예비 단어 중 최종 50 개의 단어를 선정하였다. 본 연구에서 최종 선정한 50 개 단어 내 음소(초성 및 종성 자음, 모음)와 선행연구(Byun et al., 2005)의 음소(초성 및 종성 자음, 모음) 빈도 분포도를 비교하여 Figure 1에 제시하였다.

2단계: 음원 녹음 및 편집

본 연구에서는 최종 선정한 50 개의 단어로 조합 가능한 문 장 음원 1,500 개를 제작하고자 하였다. 본 연구에서는 "주어 (name), 형용사(adjective), 목적어(object), 수사(numeral), 동 사(verb)"의 순서로 단어를 조합하였을 때 문장이 자연스러울 것에 초점을 두었다. 이를 위해 전문 음향녹음 무음실에서 현 재 성우로 활동하고 있는 여성화자의 목소리로 문장 내 동일한 단어를 10 번씩 반복하여 읽도록 녹음하였다. 녹음 시 $\mathrm{Neu}-$ mann TLM 102 (Georg Neumann GmbH, Berlin, Germany) 마이크로폰, Apogee PSX-100 (Apogee Electronics Corp, Santa Monica, CA, USA) analog to digital converter, MacBook Pro (Apple INC Cupertino, CA, USA)를 사용하였다. 마이크와 화자 사이의 거리와 강도가 일정하도록 유지하면서 보통 대화속도로 녹음할 것을 지시하였다. 음원 제작 시 사용 한 표본화 주파수와 비트는 $22,050 \mathrm{~Hz}$ 와 16 비트였고 wav형식 의 파일로 컴퓨터 하드디스크에 저장하였다.

Adobe Audition CC 2015 (Adobe Systems Inc, San Jose, (A, USA) 소프트웨어를 사용하여 단어의 강도를 조절하였다. 각 단어의 시작과 다음 단어 시작의 바로 앞부분을 포함하여 분리하는 편집(cutting) 작업을 진행하였고, 동시조음(coartic-

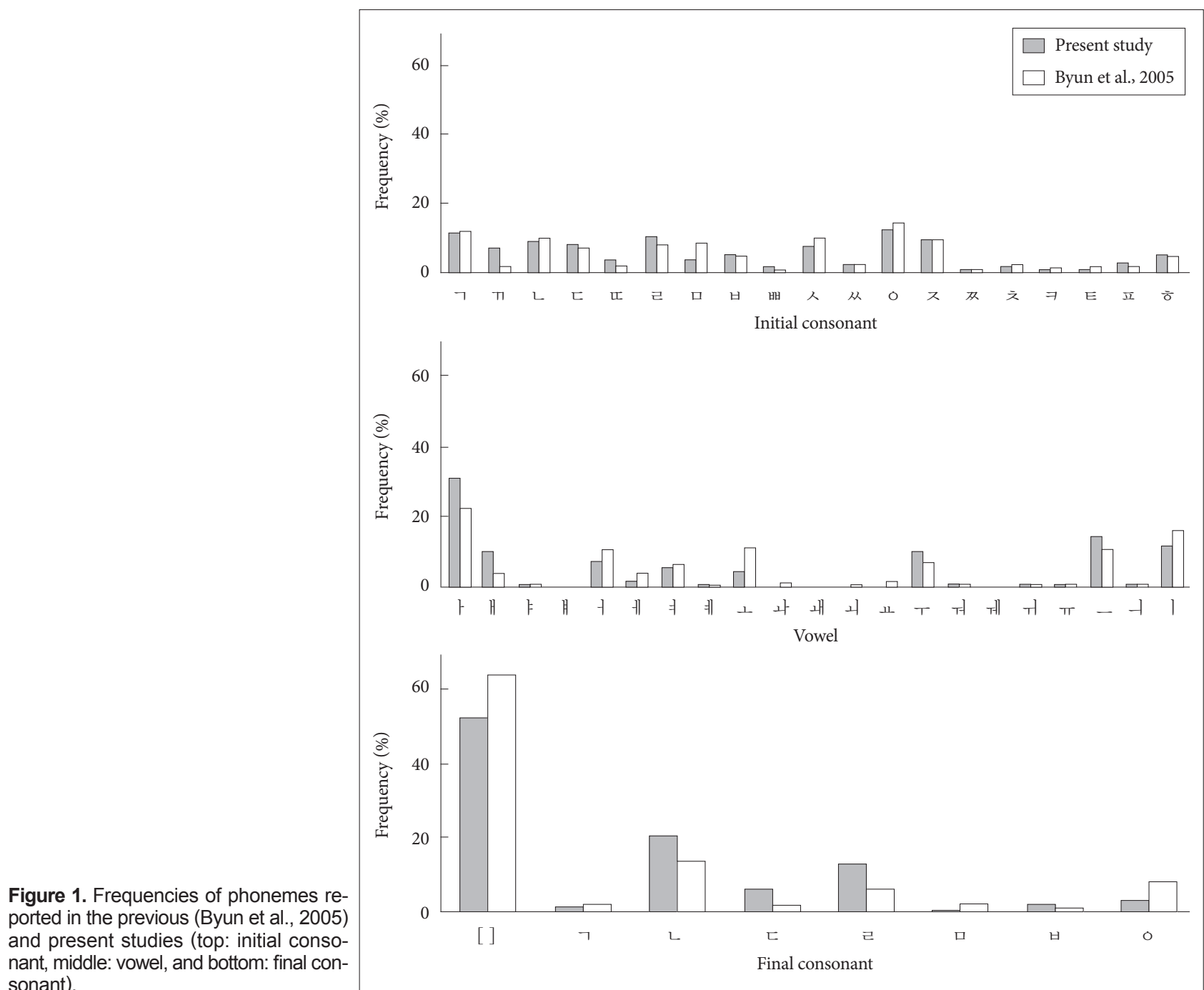


ulation)을 고려하여 분리된 단어를 임의 합성하여 1,500 개의 문 장 음원을 제작하였다. 앞서 설명한 바와 같이 50 개의 단어가 1,500 개의 문장음원 내에 같은 빈도수로 등장하게 하였다. 최 종 제작된 1,500 개의 문장과 8 명의 화자로 구성된 다화자소음 (Shin \& Lee, 2010)을 믹싱하여 4가지 소음 하 듣기조건(0, 3, $6,9 \mathrm{~dB} \mathrm{SNR})$ 의 음원을 제작하였다.

\section{3단계: 건청성인을 대상으로 한 문장음원의 검증 절차}

문장 도구의 검증은 소음수준이 1 분간 측정했을 때 $45 \mathrm{~dB}$ LAeq 이하인 검사실에서 시행하였다(sound level meter, model TES-52A, TES Electrical Electronic Corp., Taipei, Taiwan). 각 문장은 $75 \mathrm{~dB}$ SPL에서 제시하였고, 청자는 정면에 약 1미터 떨어져 위치한 컴퓨터 스피커(DB-Z400 G620; Samsung, Seoul, Korea)로 문장을 듣고 컴퓨터 화면에 제시된 보기 중에 서 들은 단어를 선택하였다. 앞에서 기술하였듯이 각 문장은 5 개의 단어로 구성되고 단어별로 각각 10 개의 보기가 존재하므 로, 청자는 문장을 듣고 50 개의 보기에서 들은 단어 5 개를 차 례로 선택하였다. 본 연구에서 개발한 객관식형 문장도구는 조 용한 상황뿐 아니라 소음이 있는 상황에서도 활용할 수 있으 므로 조용한 상황과 소음상황 모두에서 도구의 검증을 시행하 였다. 가장 쉬운 상황인 조용한 상황에서 어려운 상황 순서로 (9, 6, 3, $0 \mathrm{~dB}$ SNR 순으로) 문장음원을 제시하였다. 문장 내 단어 5 개 중 몇 개를 맞추었는지를 백분율(\%)로 환산하여 대상 자의 문장인지도를 확인하였다.

\section{4단계: 통계 분석}

5 개의 듣기조건(조용한 상황, $0,3,6,9 \mathrm{~dB}$ SNR의 소음상황) 간 문장인지도가 유의하게 달랐는지 확인하기 위해 듣기조건을 그룹 내 독립변수로, 문장인지도(\%)를 종속변수로 하여 반복측 정된 일원배치 분산분석(one-way ANOVA with repeated measures)을 실시하였다. 분석에 사용한 소프트웨어는 SPSS version 20.0 (IBM Corp., Armonk, NY, USA)이었다.

\section{RESULTS}

\section{검증 결과}

5 개의 듣기조건(조용한 상황, $0,3,6,9 \mathrm{~dB}$ SNR의 소음상황) 에서 22 명의 문장인지도를 측정하였다. 5 개의 듣기조건 중 3 개 의 듣기조건(조용한 상황, $9 \mathrm{~dB} \mathrm{SNR,} 6 \mathrm{~dB}$ SNR)에서 22명의 대상자 모두 $100 \%$ 의 문장인지도를 보였다. $3 \mathrm{~dB} \mathrm{SNR}$ 의 조건 에서는 22 명 중 1 명의 대상자가 $98 \%$ 의 문장인지도를 보였고 나머지 21 명 모두 $100 \%$ 의 정답률을 보였다. $0 \mathrm{~dB} \mathrm{SNR}$ 조건의 경우 4명의 대상자가 96 98\%의 문장인지도를 보였고, 나머지
18 명은 $100 \%$ 의 문장인지도를 보였다. 평균 정답률을 통해 예 측할 수 있듯이 통계분석 결과 SNR에 따라 문장인지도가 다르 지 않아 $[\mathrm{F}(1.2,25.4)=3.6, p>0.05]$ 소음레벨에 상관없이 본 연구에서 개발한 객관식형 문장음원을 듣고 맞추는 데 어려움 이 없음을 확인하였다.

\section{DISCUSSIONS}

본 연구에서는 문장을 구성하는 5 개의 단어를 보기 안에서 선택하는 객관식형(multiple-choice) 문장목록을 개발하고 예 비평가를 시행하였다. 모든 문장은 "주어, 형용사, 명사, 수사, 동사"의 단어 순서로 구성하였고, 5 개의 단어로 조합 가능한 $10^{5}$ 개의 문장 중 최종 1,500 개의 문장을 선정한 후 녹음하였다. 예비평가를 위해 조용한 상황과 소음상황 모두에서 건청 성인 이 문장을 듣고 50 개의 보기 안에서 문장 내 5 개의 단어를 모 두 옳게 기억하고 맞출 수 있는지를 확인하고자 하였다. 검증 결과 소음 유무에 상관없이 각 문장에 포함된 단어를 $95 \%$ 이 상 맞추었다. 이와 같이 정답률이 우수하였던 이유는 각 단어 당 10 개의 동일한 보기를 반복적으로 제시하였기 때문에 건청 인이 이를 기억하고 맞추는 데 어려움이 없었던 것으로 판단된 다. 본 연구와 유사하게, 5 개의 단어로 이루어진 객관식형 문장 을 사용한 Humes et al.(2014)은 ICRA 소음 속에서 객관식형 문장을 제시하였을 때 문장보다 소음의 강도가 더 큰 조건에서 40 70\%의 문장인지도를 확인하였다.

이와 같이 보기를 통해 문장 내 단어를 맞추는 폐쇄형(closedset) 청능훈련 도구는 기존의 전통적인 개방형 훈련도구에 비 해 아래에 나열한 장점을 가질 수 있다. 첫째, 개방형 훈련에서 는 한정된 수의 문장을 반복적으로 제시하여 훈련을 하게 되 므로 문장을 쉽게 예측하거나 경우에 따라 외울 수 있다. 이와 달리 객관식형 문장은 여러 단어의 조합으로 이루어지므로 많 은 수의 문장 생성이 가능하다. 본 연구에서는 50 개 단어의 조 합으로 최대 $10^{5}$ 개의 문장을 생성할 수 있으므로 기존에 사용 된 문장에 비해 문맥적 힌트 등을 통해 단어를 예측하기 어렵다. 둘째, 객관식형 문장이므로 소음의 강도 등 듣기 조건을 변경하 지 않고도 보기의 수를 줄이거나 늘리는 것으로 난이도 조절이 용이하다. 어휘적 빈도(lexical frequency)를 고려하여 600개의 고빈도 단어를 이용한 폐쇄형 청능훈련을 시행한 Humes et al.(2009)은 보기가 있는 청능훈련을 시행하였음에도 불구하고 보기 없이 문장을 따라 말하는 인지능력이 개선되었다고 보고 하였다. 즉, 폐쇄형 혹은 객관식형 청능훈련 도구가 일상에서의 의사소통 능력을 향상시키는 데 도움이 될 수 있음을 밝혔다. 셋째, 훈련시행 후 채점이 편리하며 보기 안에서 답을 고르므 로 대상자의 오류패턴을 쉽게 파악할 수 있다. 넷째, 청자가 미 
리 제시한 보기 안에서 들은 단어를 맞추게 되므로 심리적으 로 더 편안하고 흥미를 가질 수 있다. 실제로 폐쇄형과 개방형 청능훈련 모두에 참여한 난청인이 폐쇄형 청능훈련 시 보다 편 안하고 흥미로웠다고 답하였고 개방형 청능훈련 시 다소 초조 하고 좌절감을 느꼈다(Lee, 2015). 그러나 본 연구에서는 60대 이상의 노년층 청자를 대상으로 하지 않았으므로 후속 연구를 통해 노인 청자를 대상으로 객관식형 문장 도구의 검증을 지속 해야 한다.

최근에는 한 가지 종류의 자극음을 단순히 따라 말하는 기 존의 훈련방법의 단점을 극복하기 위해 다양한 자극음을 활용 한 연구가 다수 보고되었다(Humes et al., 2014; Lee, 2015; Tye-Murray et al., 2012). Humes et al.(2014)은 5가지 종류의 훈련 자극음을 사용하였고, Lee(2015)는 총 4가지의 개방형 혹 은 폐쇄형 훈련을 시행하였다. 다화자 혹은 단화자의 음원을 이용하여 청능훈련을 총 93명의 난청인에게 컴퓨터를 이용한 청능훈련을 시행한 Tye-Murray et al.(2012)은 6주간의 청능훈 련 효과만을 측정한 것뿐 아니라 훈련도구에 대한 부정적인 혹 은 긍정적인 면을 조사하였다. 분석 결과 주관적인 훈련 효과와 훈련 시 대상자가 얼마나 즐겼는지 정도는 관련성이 없었고, 향 후 보다 즐길 수 있고 덜 지겨운 도구의 개발이 필요하다고 밝 혔다. 현재 국내에서 개발된 청능훈련용 음원으로는 환경음 (Ahn \& Lee, 2016), 가로세로 단어퀴즈(Baek \& Lee, 2016), 문 장(Jang \& Lee, 2016), 이야기(Lim \& Bahng, 2016) 등이 있으 나 난청인을 대상으로 소음 상황에서의 검증이 더 필요하다. 향 후 연구에서는 난이도 조절을 통하여 훈련 시 대상자가 너무 어 려움을 느끼지 않으면서도 즐겁게, 흥미를 가지고 참여할 수 있 도록 훈련 절차를 정립해야겠다. 또한, 단순히 반복하여 말하기 보다는 청각적 집중력, 단기 및 장기 기억, 연상 활동을 포함하 는 종합적 청능훈련 도구의 개발이 지속되어야겠다.

중심 단어 : 객관식형 문장·소음 하 청능훈련·폐쇄형 청능훈련.

\section{REFERENCES}

Ahn, P. H. \& Lee, K. (2016). Development of environmental sounds for auditory training. Audiology and Speech Research, 12(2), 82-88.

Akeroyd, M. A., Arlinger, S., Bentler, R. A., Boothroyd, A., Dillier, N., Dreschler, W. A., et al. (2015). International Collegium of Rehabilitative Audiology (ICRA) recommendations for the construction of multilingual speech tests. ICRA Working Group on Multilingual Speech Tests. International Journal of Audiology, 54(Suppl 2), 17-22.
Baek, S. S. \& Lee, J. H. (2016). Development of crossword puzzles for auditory training. Audiology and Speech Research, 12(2), 103-108.

Burk, M. H. \& Humes, L. E. (2008). Effects of long-term training on aided speech-recognition performance in noise in older adults. Journal of Speech, Language, and Hearing Research, 51(3), 759-771.

Byun, S. W., Kim, J. K., Lee, S. S., \& Bae, J. H. (2005). Excessive post-obstruent tensing in Korean spondee word list: comparison between the colloquial Korean language and Hahm's list. Korean Journal of Otorhinolaryngology Head and Neck Surgery, 48(5), 596-600.

Chang, S. \& Lee, J. (2016). Development of auditory training tool for adults using sentences. Audiology and Speech Research, 12(2), 89-96.

Cho, Y. Y., Lee, J. H., \& Bahng, J. (2013). Case study of auditory training for an elderly hearing aid user. Audiology, 9(2), 190-194.

Henshaw, H. \& Ferguson, M. A. (2013). Efficacy of individual computerbased auditory training for people with hearing loss: a systematic review of the evidence. PLoS One, 8(5), e62836.

Humes, L. E., Burk, M. H., Strauser, L. E., Kinney, D. L. (2009). Development and efficacy of a frequent-word auditory training protocol for older adults with impaired hearing. Ear and Hearing, 30(5), 613-627.

Humes, L. E., Kinney, D. L., Brown, S. E., Kiener, A. L., \& Quigley, T. M. (2014). The effects of dosage and duration of auditory training for older adults with hearing impairment. The Journal of the Acoustical Society of America, 136(3), EL224-EL230.

Kim, H. G. \& Lee, K. W. (2010). Effects of word recognition score as a function of auditory training terms for elderly hearing impaired with hearing aid. Audiology, 6(2), 159-163.

Kwon, Y. J. (2014). Effects of 8-week auditory training: Compressed speech and speech in noise (unpublished master's thesis). Hallym University of Graduate Studies, Seoul.

Lee, S. G. (2015). Effects of 10 -week auditory training for hearing aid users using closed-set and open-set materials (unpublished master's thesis). Hallym University of Graduate Studies, Seoul.

Lee, Y. S. (2011). Effects of training on nonsense syllable performance in noise for older hearing aid users (unpublished master's thesis). Hallym University of Graduate Studies, Seoul.

Lim, E. H. \& Bahng, J. (2016). Preliminary study for development of auditory training tool using story and question. Audiology and Speech Research, 12(2), 109-114.

Morais, A. A., Rocha-Muniz, C. N., \& Schochat, E. (2015). Efficacy of auditory training in elderly subjects. Frontiers in Aging Neuroscience, 7, 78.

Shin, J. (2008). Phoneme and syllable frequencies of Korean based on the analysis of spontaneous speech data. Communication Sciences and Disorders, 13(2), 193-215.

Shin, J. B. \& Lee, J. H. (2010). Effects of the target talker gender and the number of competing talkers on Acceptable Noise Level (ANL) of Korean normal-hearing adults. Audiology, 6(2), 146-152.

Stecker, G. C., Bowman, G. A., Yund, E. W., Herron, T. J., Roup, C. M., \& Woods, D. L. (2006). Perceptual training improves syllable identification in new and experienced hearing aid users. Journal of Rehabilitation Research and Development, 43(4), 537-552.

Tye-Murray, N., Sommers, M. S., Mauzé, E., Schroy, C., Barcroft, J., \& Spehar, B. (2012). Using patient perceptions of relative benefit and enjoyment to assess auditory training. Journal of the American Academy of Audiology, 23(8), 623-634.

Yeo, S. H., Bahng, J. H., \& Lee, J. H. (2014). Efficacy of auditory training using sentences in noise for hearing aid users. Audiology, 10(1), 65-75. 


\section{APPENDIX}

Examples of 5-word sentences for auditory training

\begin{tabular}{ccccc}
\hline Name & Adjective & Object & Numeral & Verb \\
\hline 건우는 & 새로운 & 책상 & 한 개를 & 본다 \\
철수는 & 작은 & 의자 & 두 개를 & 받았다 \\
유진이가 & 멋진 & 바구니 & 여덟 개를 & 산다 \\
\hline
\end{tabular}

